\title{
In situ Analytical TEM of Ilmenite Reduction in Hydrogen
}

\author{
Arne Janssen ${ }^{1}$, Eric Prestat ${ }^{1}$, Matthew Smith ${ }^{1}$, Sarah J. Haigh and M.G. Burke ${ }^{1}$ \\ ${ }^{1 .}$ Materials Performance Centre, School of Materials, The University of Manchester, Manchester, UK.
}

Ilmenite $\left(\mathrm{FeTiO}_{3}\right)$ is an important mineral, formed in igneous and metamorphic rocks, and is the main feedstock for the titanium industry. Ilmenite is also an attractive and inexpensive oxygen carrier for chemical-looping combustion (CLC), one of the most promising technologies to accomplish $\mathrm{CO}_{2}$ capture in power plants [1]. The technique uses solid metal oxides as an oxygen carrier, which transfers oxygen from the combustion air to the fuel. The metal oxide reacts with a hydrocarbon fuel in the fuel reactor, to produce $\mathrm{CO}_{2}$ and $\mathrm{H}_{2} \mathrm{O}$ while reducing the metal oxide. However, detailed information about structural and chemical changes of ilmenite during the reduction process are still not available. The understanding of structural and chemical relationships at the nanometer scale during the oxygen transfer is essential because it can be help to understand the exact reduction mechanism of the oxygen carrier, and hence optimise the combustion process.

In situ analytical TEM has huge potential of providing nano-scale information of chemical reactions and structural transformations occurring in atmospheric environments. Due to new developments in in situ holders there is now the possibility of combining in situ TEM studies with the best microanalytical aspects of a modern AEM.

In situ reduction experiments have been performed using the new Protochips Atmosphere In Situ Heating and Gas Reaction Cell (Protochips Inc.). The specimens for this investigation were obtained from Norwegian hard rock ilmenite, which was ground with ethanol. Droplets of this suspension were deposited on the surface of the heater E-chip. The reduction of ilmenite was carried out at $470{ }^{\circ} \mathrm{C}$ in 950 mbar $\mathrm{H}_{2}$. Analytical transmission electron microscopy investigation has been carried out using a spherical aberration corrected FEI Titan G2 80-200 with ChemiSTEM technology, operated at $200 \mathrm{kV}$ and equipped with a GIF Quantum ER. Energy Electron Spectroscopy (EELS) and X-ray Energy Dispersive Spectroscopy (XEDS) in STEM have been used to map regions of interest to observe chemical changes during the reduction process.

Our first results give some insight on the reduction mechanism of ilmenite. STEM-EELS and XEDS spectrum images yielded that the decomposition of ilmenite to titanium and iron take place at relative low temperature, resulting in restructuring of the overall morphology of the initial grains (Fig1\&2). Iron particles are formed with a non-uniform distribution around the surface. The density of the particles increases with time and temperature. The formation of the particles is the result of volume diffusion of iron towards the surface of the grains, while Ti is not mobile at temperature below $900{ }^{\circ} \mathrm{C}$ [2]. A volume reduction of approximately $40 \%$ causes the formation of porosity in the residual $\mathrm{TiO}_{2}$. EEL spectrum imaging of the oxygen K-pre-edge indicate that most of the iron is still covalent bonded with oxygen and not reduced to metallic iron (Fig2e) [3]. The oxidation state of the iron sub-oxides is currently unknown; further EELS studies will be used to clarify the oxidation state of the iron particles. 
References:

[1] H. Leion et al, Chemical Engineering Research and Design, 9 (2008), p. 1017-1026.

[2] D.B. Rao, M Rigaud, Oxidation of Metals, 9 (1975), p. 99-116.

[3] P.A. van Aken et al, Phys Chem Minerals, 25 (1998), p. 494-498.

[4] We acknowledge BP for financial funding. The authors thank Matthew A. Kulzick and Nestor J. Zaluzec for helpful discussions.
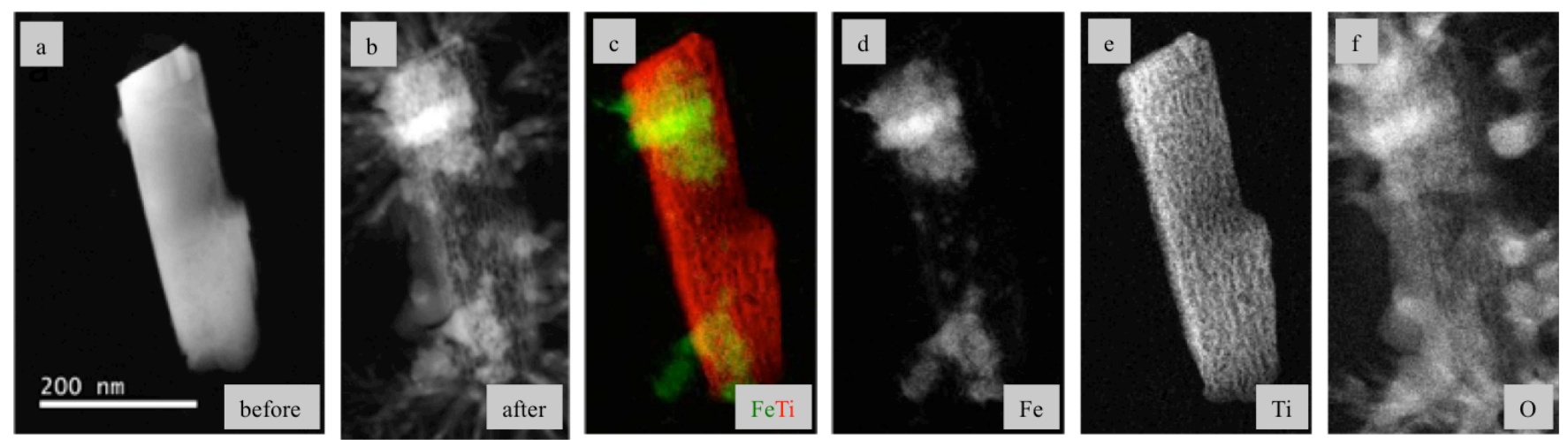

Figure 1. STEM-HAADF images before (a) and after (b) hydrogen reduction, XEDS elemental maps (c-f) of the decomposed ilmenite.
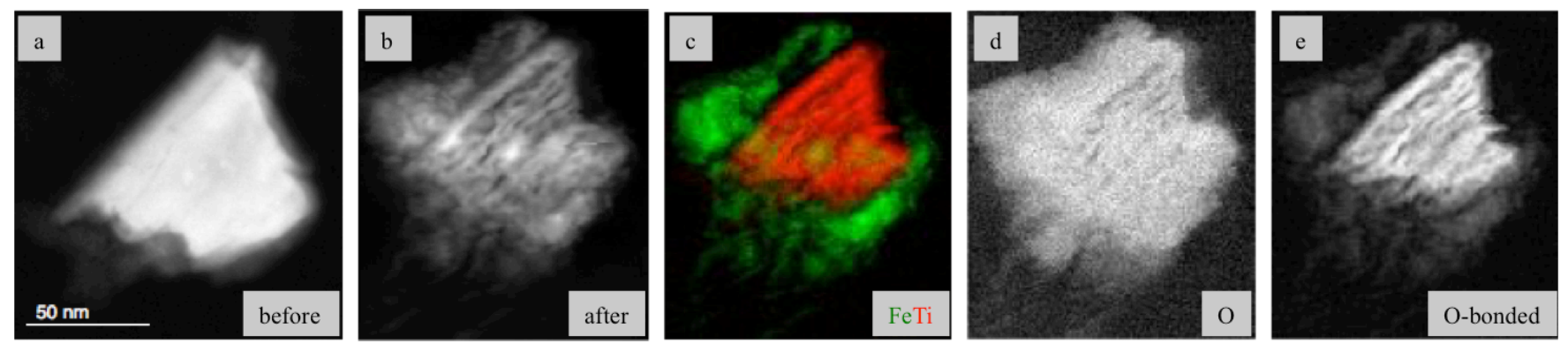

Figure 2. STEM-HAADF images before (a) and after (b) hydrogen reduction, (c) EELS elemental maps showing the $\mathrm{Fe}$, Ti and $\mathrm{O}$ distribution in the decomposed ilmenite, (e) $\mathrm{O} \mathrm{K}$-pre-edge map at $530 \mathrm{eV}$ indicating covalent bonding of oxygen with iron or titanium. 